\title{
Prospects for the Third Sector
}

\author{
Mark Crowe ${ }^{1}$, Chris Dayson 2 and Peter Wells ${ }^{2 *}$ \\ ${ }^{1}$ Yorkshire and Humber Regional Forum \\ 2Sheffield Hallam University
}

\begin{abstract}
This paper explores the prospects for the Third Sector following the next General Election in the United Kingdom. The paper provides a context for understanding the third sector and some of the key agendas which will impact upon it, including its role in the delivery of public services, the implications of public expenditure cuts, the shift in funding models for the sector including both social investment and personalisation, localism and the demonstration of impact and value for money. Although the paper finds cause to expect much continuity in terms of third sector policy (whichever party wins the election), it also identifies three notable fault lines. These are around the relationship between state and society, resources and scale, and equity and disadvantage. Given the wider context for third sector policy, it is anticipated that 2010 will mark a significant disjuncture in the development of the third sector.
\end{abstract}

Keywords: third sector, General Election, civil society, big society, social investment.

\section{Setting the scene}

The policy, economic and public expenditure climates in 2010 are very different from 2000. Senior commentators on the third sector have referred to the last ten years as a golden decade for the sector. The annual Almanac on the state of the third sector published by the National Council for Voluntary Organisations have charted the growth of the sector through the last decade which has only reversed in the last couple of years. Much of this growth has been driven by state funding of the sector, to some extent through grants but largely through its growing role in the delivery of public services.

Any commentary on the sector must emphasise its diversity: it ranges from major NGOs such as Oxfam and Shelter through to charities operating at local and regional levels and to often uncrystalised community groups of individuals. Although the NCVO estimate that there are around 170 thousand charities in the United Kingdom, wider civil society may include upwards of 800,000 groups in total. There is also no singular legal form of third sector organisation: it includes registered charities but also not-forprofit companies, industrial societies, housing associations, mutual organisations (such 
as some building societies) and newly created legal forms such as companies limited by guarantee; as well of course of groups of individuals coming together for a common purpose and requiring no registered legal status to do so. Although there has been considerable interest in social enterprise, largely as a means for delivering public services, it is not a distinct legal form and may take many of the forms discussed above: to this end it is as much a verb as a noun.

The increasing role of the third sector in the delivery of public services, in 2006/07 it received 37 per cent of its funding from statutory sources - something which has also increased its vulnerability to public expenditure cuts, as well of course to downward pressure on other core sources of income such as donations, legacies, investment income and grants from charitable trusts. How these effects play out will be uneven and such effects will be transmitted through myriad mechanisms. It is also notable that there is considerable variation in income sources across charities, for instance with many major charities able to raise substantial income through donations. Although there are high profile employment cuts by major charities, there is also some consensus that smaller and medium sized charities (often with incomes from $£ 50$ thousand to $£ 1$ million) and with relatively small numbers of paid staff will be hardest hit. Conversely, small organisations which rely wholly on voluntary action are far less vulnerable; there may also be some contraction back into the use of volunteers by some small charities.

As such it is necessary to recognise that the third sector does not just deliver public services. It plays a significant and multi faceted role in advocacy, influence and agenda setting: put simply, championing and campaigning for disadvantaged groups and individuals.

\section{The Third Sector terrain after the election}

At both national and local levels the following issues and agendas will shape the future of the third sector. First, the position of the third sector in the delivery of public services will remain high on the agenda. How this is achieved is reflected on below, but it seems likely that services in areas such as health and social care, education and learning, and crime will place considerable emphasis on the role of the third sector.

Second, and as signified above, the sector will undergo a further period of rationalisation and contraction. Effects due to the recession and public expenditure cuts are anticipated to fall most heavily on smaller and medium sized charities. It can also be anticipated that there may also be geographic variations, with the sector in northern regions of England, Scotland and Wales facing particular pressures with dramatic reductions in funding from domestic and European Union regeneration programmes. These effects may be most acute for organisations working in disadvantaged neighbourhoods.

Third, there will be continued reworking of (public) funding models for the sector. These are in terms of direct funding (primarily through grants) but also indirectly with a continuation of larger scale public service contracts with requirements for the third sector to enter into sub-contracting agreements with public, private and large third sector contractors but also agendas such as personalisation (or co-production) of services. Both bring challenges to the sector, albeit the top-down commissioning model likely to remain a key agenda. Funding agendas informed by the principles of social investment will also continue, and notably the use of combined loan funding.

Fourth, agendas around localism may become more dominant with central government powers ceded to local authorities and with greater civil engagement in an 


\section{p. 31. Prospects for the Third Sector}

array of arenas. These should present new opportunities to the third sector, and especially to locally based and connected organisations. However, requirements for local authorities to cut expenditure may mean some withdrawal from what are seen as riskier and more experimental forms of co-production of services with the preference for large scale commissioning. Similarly, the raison d'être of the sector around preventative work may be marginalised as local funders have to focus on core (e.g. care and curative) provision.

Finally, there will be increasing scrutiny of value for money and in particular cost efficiency (more outputs for less) but also cost efficiency (more outcomes for less) issues. On the one hand embedding outcomes measurement within organisations is seen as a necessary part of the modern third sector organisation, but on the other, the terrain third sector organisations often work with (e.g. individuals with complex needs) can make outcome measurement far from straightforward. This raises a question which is whether pressure on costs and requirement to demonstrate 'difficult' outcomes may suppress the traditional strength of the sector around service innovation.

Each of these issues or agendas will have differential effects across the sector. This will bring opportunities for many individuals and organisations but also increasing and untenable pressures for others. There will be considerable pressure on individuals and organisations in the sector to navigate these new agendas in what will is likely to be a highly charged and competitive environment for resources.

\section{Election as disjuncture or continuum}

A previous article in this journal speculated on whether a Conservative government would represent continuity or change in third sector policy. It concluded that continuity was the more dominant theme and this is reflected in the above commentary. However, the article also suggested that areas of difference would emerge closer to the election; there appear both similarities and clear differences in the positions of the two main political parties.

Both parties place some emphasis on civil society, although it is notable that there are differences in language here. Labour actively uses the term third sector in all policy announcements, reflecting its policy commitments and the establishment of an Office of the Third Sector. However, notions of a sector have diminished in Conservative Party announcements, with the term "Big Society" used as an expression of civil society and with the third sector only referred to when discussing the Labour Government's policies. Elsewhere both parties place emphasis on community and neighbourhood action as well as a commitment to social investment; the latter primarily in discussions around the "Social Investment Wholesale Bank" (Labour) and "Big Society Bank" (Conservatives).

The areas of difference come from three substantive areas: the relationship between state and society, resources and scale, and equity and disadvantage. The Labour Government placed considerable emphasis on the role of the third sector in the delivery of the public services; and this is reflected in its positions in the lead up to the election. Reforms and changes to public service delivery, and delivery of programmes such as Sure Start and New Deal for Communities, have place a strong emphasis on the third sector. By contrast the Conservative Party focus much more on a more on facilitating voluntary and community organisations to play roles in arenas which should be vacated by state intervention. These include proposals around the support of social enterprise, the stimulation of neighbourhood groups and the creation of a national 
(societal) commitment to social action, reflected in David Cameron's demands for mass engagement through a "broad culture [of] ... responsibility, mutuality and obligation."

In terms of resources and scale, as discussed, the New Labour government has been instrumental in the growth of the sector and it is anticipated that in a climate of public expenditure cuts, this growth will reverse. Nonetheless, future public expenditure commitments by both parties are much less; although perhaps far smaller by the Conservatives. Proposals to support social enterprises and neighbourhood groups from the Conservative Party do not appear to include considerable redirection of resources, rather the role of the state would be to enable and steer such social action. Again, this is a strong theme of the "Big Society" agenda which reduces, and reforms, the role of the state.

Finally there are agendas around equity and disadvantage. Although the New Labour government shifted its emphasis towards equality of opportunity and personal responsibility (especially in terms of employment policy), this was combined with large social programmes and addressing spatial and individual inequalities. The Conservative Party critique of New Labour on these issues is that it has fostered these are state-led solutions, and that the scale of the state should be both smaller but also act to enable social action.

Whatever the outcome of the General Election, the policy environment is set to change considerably. As such it will mark a policy disjuncture. The primary concern for many third sector organisations will be navigating the new policy terrain to sustain and develop their activities.

* Correspondence Address: Peter Wells, Sheffield Hallam University, CRESR, Unit 10, Science Park, Howard Street, Sheffield, S1 1WB. Email: p.wells@shu.ac.uk. 